\title{
Application of Lean Thinking to the Processing of Raw Materials: Case Study of a Company in the Biomass Torrefaction Sector
}

\author{
L. J. R. Nunes and S. G. Azevedo
}

\begin{abstract}
Currently, the market where the organizations are inserted is very competitive and the consumers are more and more demanding. As such, there is a great need to adopt more efficient management models for increasing the competitiveness of companies. Lean Manufacturing has proven to be very powerful in that point. This work aims to identify the benefits associated to the implement of the Lean philosophy in the raw material processing of a Portuguese production unit of the biomass sector named Yser Green Energy (YGE). In this case study the company and the process of production of torrefied biomass were generally analyzed. All stages of the production process were analyzed using the lean tool Value Stream Mapping (VSM). After analyzing all the steps and taking into account the data of the production process collected, the value added activities, and the non-value added activities were identified so that the latter could be eliminated. After analyzing the data obtained, actions were proposed to improve the flow of value of the YGE production process, reducing the waste generated, to make the organization more competent and more efficient. After the application of the VSM tool, and with the elimination of the detected problems, there was a clear reduction in the time of the lead time and, consequently, in the value of the process cycle efficiency (PCE). With the case study it is possible to apply the VSM tool to suggest improvements in order to reach higher levels of efficiency.
\end{abstract}

Index Terms-Lean manufacturing, VSM, torrefied biomass pellets, case study.

\section{INTRODUCTION}

With the evolution of society and, consequently, with the mass consumption of fossil fuels, a greater awareness of the potential problems associated with its consumption was reached [1].

As non-renewable energy resources and whose reserves are in nature in limited quantities and tending to depletion, fossil fuels are considered as sources of non-renewable energy. Economic and environmental factors related to their use have led, over time, to oil crises and increased air pollution, with consequent effects [2].

The main sources of biomass come from forest products (forestry operations, forest energy crops, use of woodchips), agriculture wastes (straw, olive stone, rice husk) and wastes

Manuscript received February 20, 2017; reivsed May 12, 2017. This work was supported by Fundacão para a Ciência e Tecnologia and FEDER/COMPETE (grant UID/ECO/ 04007/2013).

L. J. R. Nunes is with the Department of Economics, Management, Industrial Engineering and Tourism of the University of Aveiro, Aveiro, Portugal (e-mail: leonelnunes@ua.pt).

S. G. Azevedo is with CEFAGE - Department of Management and Economics University of Beira Interior, Covilhã, Portugal (e-mail: sazevedo@ubi.pt) derived from wood processing industries (sawmills, furniture) [3].

The energy recovery of these materials can be done in several ways: i) through direct burning without any processing of the raw material; (ii) chip burning systems in which the raw material is pre-ground; and (iii) by the manufacture and burning of wood pellets [4].

Pellets are fuels in which the raw material is crushed, dried and pressed into cylindrical form. In the pelletizing process energy densification of the fuel occurs. This fact, associated to the drying process that gives them very low humidity levels $(5-10 \%)$, gives them transport and storage benefits [5].

Biomass pellets are a sustainable energy alternative, creating wealth and local employment. Wood is relevant as a source of primary energy, especially in times of economic crisis. However, the following drawbacks can be pointed out: high cost of production, supply and costly energy conversion technologies [6].

\section{ORIGIN OF LEAN MANUFACTURING}

The Lean concept began to be developed in the 1950s by Taichii Ohno and Eiji Toyoda, within the Toyota Motor Company. Toyoda and Ohno, while visiting the Ford factory in Detroit, found some flaws, such as the fact that it produced in large quantities, which led to increased machine wear and large accumulations of material. Taiichi Ohno took on the task of increasing productivity, eliminating all waste, that is, all existing activities that did not add value to the product. This is how the Toyota Production System (TPS) came about, with principles different from those of mass production, based on the constant search for waste disposal. Later, the book "The Machine that changed the World" published the concept of the TPS designating it as "Lean Production" or "Lean Manufacturing" [7].

The main objective of this system is the elimination of unnecessary production activities, which establishes a productive method focused on customer requests and thus obtain a competitive advantage in the market. The system has as principle the development of processes through the elimination of waste, aiming at the quality and flexibility of the process [7].

Although Lean has emerged in the automotive industry, it can be applied in different types of organizations, and can even be used in services, because allows to meet customer requests with low cost and most adequate delivery times [8].

Value Stream Mapping (VSM) is a tool that was born in Toyota and was later developed and deepened by Mike Rother and John Shook. For these authors, VSM is a tool 
developed to support the implementation of Lean management in production processes. It allows all stakeholders to identify and design, in the form of a map, all the activities that take place along the value chain, from delivery of materials by suppliers to final delivery to the customer. This representation of the state of the system tries to see the processes as a whole, considering all the flows of information, materials and processes to which the product is subject [9].

VSM is more useful compared to other quantitative tools or intended to represent layouts. It is qualitative, allowing detailed description of how the productive flow should operate to create added value, and defines the direction to take [9].

To map the flow of value of a production process, it is necessary to follow a set of steps [10]:

1) The product must be monitored throughout the production system and observe what happens throughout the process. At this stage the product or family of products and the type of map to be represented are defined. Next, the "Current Value Flow Map" is created, which consists of the present value flow, where current steps, delays, material flows, and other information are presented. After the creation of this, the "Future Value Flow Map" should be defined, which presents the improvements in the current value flow, through the elimination of waste. Taking this analysis and the documented database into account, each particular process is examined in order to reduce waste, operating times and, above all, costs. Finally, a "Plan of Action" is developed to define the work plan and implement possible improvement actions. These maps, when elaborated frequently, allow to visualize the value and especially the sources of waste. The repetition of these steps allows to improve the value chain, reduce lead time and eliminate waste gradually.

2) The analysis of the communication or information flow is the next step, which allows visualizing the operation of the entire internal information flow, between the control of production and the different productive areas, as well as visualizing the flow of external information with customers and suppliers. This section also identifies the frequency with which suppliers deliver their products, as well as the frequency with which deliveries are made to customers.

3) Lastly, the time lines and distances traveled are analyzed, to indicate exactly the distances covered by the product and the times spent. The time line indicates the time required to produce a product unit at each workstation (cycle time), and the waiting time to enter the next workstation.

In order to design VSM, it is necessary, firstly, to know exactly what is the average daily demand of the product or family of products by the customer(s), in order to be able to calculate the takt-time (TT). Since it defines the frequency with which the company has to make available a unit of product to the client(s), TT influences the elaboration of the VSM. Next, the production flow is traversed, from the finished product warehouse (ready to be delivered to the customer), to the raw materials warehouse.

Subsequently, the wastes along the production flow are identified, from the shipping warehouse, to the raw material store. For this it is necessary to calculate TT, which is the maximum time required to manufacture a product unit, to satisfy the customer's need. Through the obtained result, the periodicity (in minutes) will be known, with which the company must have an end product ready to satisfy the customer's need.

A "Timeline" accompanies, at the bottom, the current and future value stream flow maps. It records the total cycle time of the process, corresponding to the value added time of the process and the delivery time of the product to the customer (lead time). The lead time analyzes the different wait times between the different activities in the production process, allowing to know how much time it takes to "actually" deliver a particular product unit to the customer. Through lead time, the company realizes that the ideal will be to reduce or if possible eliminate the stock, since having stock means having money invested and stopped.

The cycle time $(\mathrm{C} / \mathrm{T})$ is commonly represented in current and future state maps. The $\mathrm{C} / \mathrm{T}$ is the time that elapses between the beginning and the end of an activity in a production process, that is, the time for the execution of a part. The $\mathrm{C} / \mathrm{T}$ means the time for the operator to complete the duty cycle for a unit. It is very important that the $\mathrm{C} / \mathrm{T}$ value is close to TT because it means that there is control of the production process. If the $\mathrm{C} / \mathrm{T}$ is lower than $\mathrm{TT}$, the process can generate waste by overproduction and too many resources may be used. If $\mathrm{C} / \mathrm{T}$ is higher than $\mathrm{TT}$, it means that customer orders can not be satisfied.

Finally, VSM is calculated by Value-Added (VA). The VA time consists of the sum of the C/T of all activities, which truly add value to the final product. The VSM should be complemented by Process Cycle Efficiency information (PCE) [11].

\section{BIOMASS CONVERSION THROUGH TORREFACTION}

Biomass torrefaction consists of a process of refinement and thermal pre-processing (temperatures ranging from $200^{\circ} \mathrm{C}$ to $350^{\circ} \mathrm{C}$ ). The process has as functions to increase calorific value, water resistance, friability and increase energy density [12].

The final powdered product resembles pulverized coal in terms of fuel supply and combustion behavior. In order to maximize the logistical and handling advantages of the systems, torrefaction is used as early as possible in the supply chain of biomass conversion systems.

\section{CASE STUDY}

\section{A. Application of VSM to the production process}

In order to identify and minimize or, if possible, eliminate existing waste in the production process, Lean Management was implemented in the company YGE SA (Portugal). VSM was used, since it was considered the tool with the most capacity to identify and analyze the wastes existing in the production process from obtaining the raw material until the delivery of the final product to the customer. 
Subsequently, the opportunities for improvement were identified and the future value flow was defined and the actions to be taken in order to achieve the desired future value flow were planned as described next [12-16]:

1) Mapping the YGE production process value stream (current value stream representation - current VSM).

2) Analysis of the current value flow of YGE.

3) Identification of improvement opportunities (identification of waste and proposal of improvement actions to achieve the flow of future value of YGE).

4) Definition of the YGE future value stream (representation of the future value stream - future VSM).

5) Plan of action on the improvement opportunities identified in the Future Value Stream.

\section{B. Product Analysis}

The first phase of VSM is to analyze and identify the most representative products for the company. Generally, there are many products and complex flows between them, which makes it difficult to select the most significant product for the application of Lean practices [17].

In the specific case of the company YGE, this difficulty does not exist, since there is only one product present along the whole line of production of pellets of torridated biomass: the raw material forest biomass.

\section{Current State Analysis}

After the selection of the product, it is analyzed the value chain of the same, with the purpose of analyzing what occurs "currently" in the YGE production process.

As the VSM itself suggests, it is necessary to draw up a diagram in order to obtain the graphical representation of the material flows associated with the product. Since the processes to which the product is subject have already been explained in detail, the phases of the product are then presented succinctly and the product passes through until it reaches its final state within the unit. With this analysis it was identified a set of wastes in some activities [18].

The current VSM was then elaborated to present the current state of the product value chain. By going through the productive flow and consulting all workers involved in this process, it was possible to collect the data of each job and each process, such as: cycle time, lead time, number of employees per process, number of shifts, movements and stocks. It was also calculated the takt-time (TT), in order to know how often the customer wants to be served.

In order to determine the time necessary for the activities of each process to be performed, the cycle time of each process and then the Total Cycle Time of the production process (Total T/C) were calculated. The following method was used to determine each cycle time $(\mathrm{C} / \mathrm{T})$ : each process was observed and, with the use of a stopwatch, the execution time of each one was recorded (Table I).

TABLE 1: CyCle TIME OF EACH PROCESS

\begin{tabular}{cc}
\hline Process & $\begin{array}{c}\text { Cycle time } \\
\text { (Minutes) }\end{array}$ \\
\hline Shredding & 10 \\
Milling & 6
\end{tabular}

\begin{tabular}{cl} 
Drying & 4 \\
Milling & 6 \\
Sieving & 4 \\
Torrefaction & 8 \\
Cooling & 6 \\
Pelletizing & 6 \\
Cooling & 6 \\
Sieving & 4 \\
\hline
\end{tabular}

At the end of the observations of all the processes were added all $\mathrm{C} / \mathrm{T}$, obtaining the Total $\mathrm{C} / \mathrm{T}$, ie Value Added Time (VA). The value obtained for the process cycle was 60 minutes.

In order to determine the lead time, 20 minutes were recorded until the first process (shredding) was started. These minutes correspond to the time interval between the moment the loader collects the raw material from the park floor after the wood shredder and deposits it in the first step of the industrial process [19].

In order to calculate the lead time, the stock was also accounted for in the case of production line stops and in case the buffers need to be activated in order to prevent unnecessary stops.

After the process analysis, the following result was obtained for Lead Time: Lead Time $=20+60+18=98$ min. This means that the time required between the time of entry of the raw material to the exit of the processes and being available for dispatch is 98 minutes.

Based on the values obtained, it is possible to calculate the process cycle efficiency (PCE) in its current state (Eq. $1)$ :

$$
P C E=\frac{98-60}{98} \times 100=39 \%
$$

The result obtained for the PCE, 39\%, fits in a typical value of a company that does not have any type Lean tool implemented in its industrial processes.

In the case of pellets of torrential biomass the customer has an average order of 378,000 tons per month, 18,000 tons per day. The available time is 15 hours $(54,000$ seconds), which corresponds to two shifts. Thus, takt-time is equal to (Eq. 2):

$$
T T=\frac{54000}{18000}=3 \text { seconds }
$$

It turns out that in one process only one shift works. In this case, the takt-time is calculated with an available time of one shift only, that is, 27000 seconds to divide equally by the total request. In this case, $\mathrm{TT}=1.5$ seconds.

The current VSM is based on the data collected (Figure 1). Its elaboration involved workers from different areas, not only to obtain the data more reliably, but also to have greater motivation and awareness for the implementation of Lean practices, particularly the VSM. From the current VSM, it is possible to improve and then create the future VSM.

When analyzing the productive process of the company YGE, the following problems were identified which could cause waste in the flow of value: 


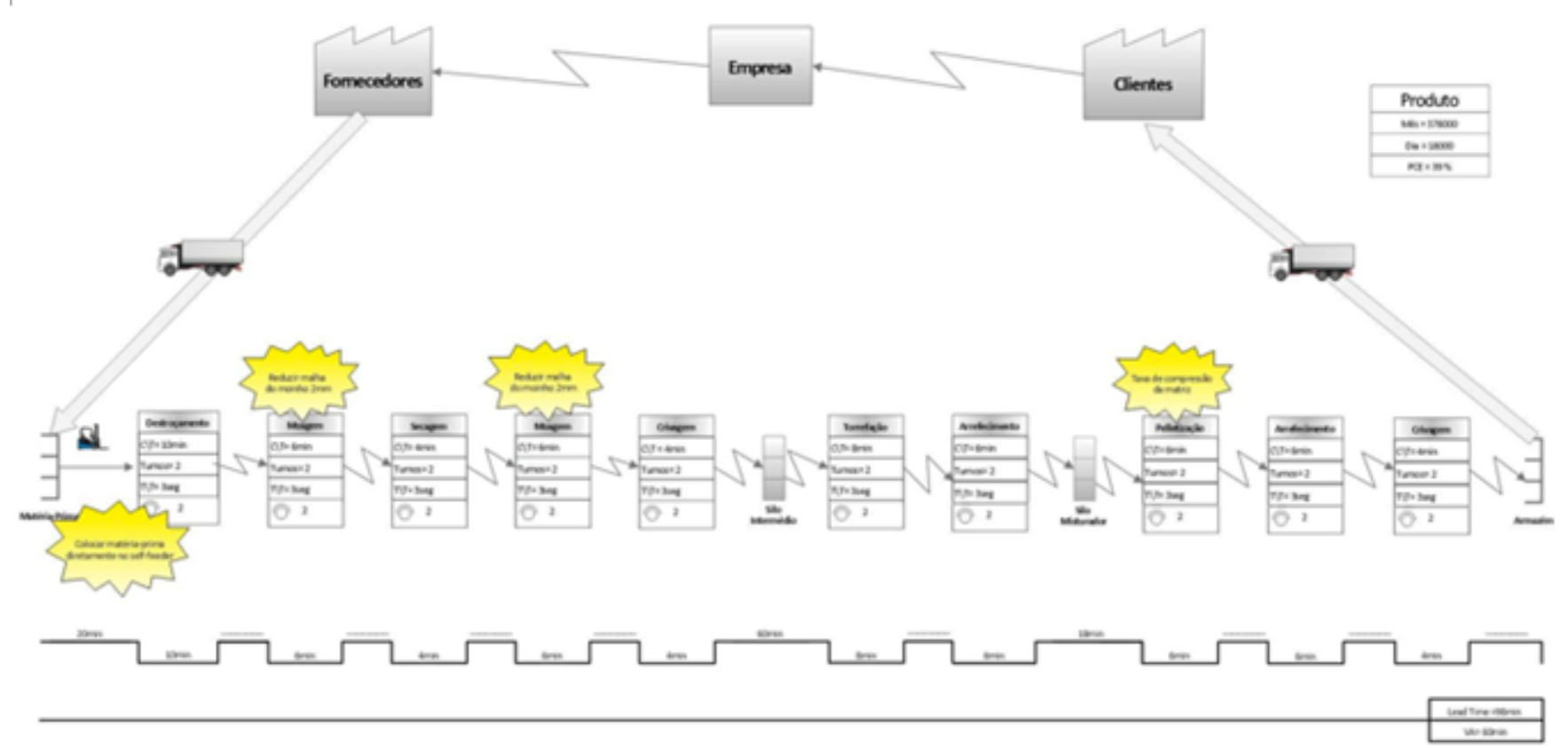

Fig. 1. VSM, current state.

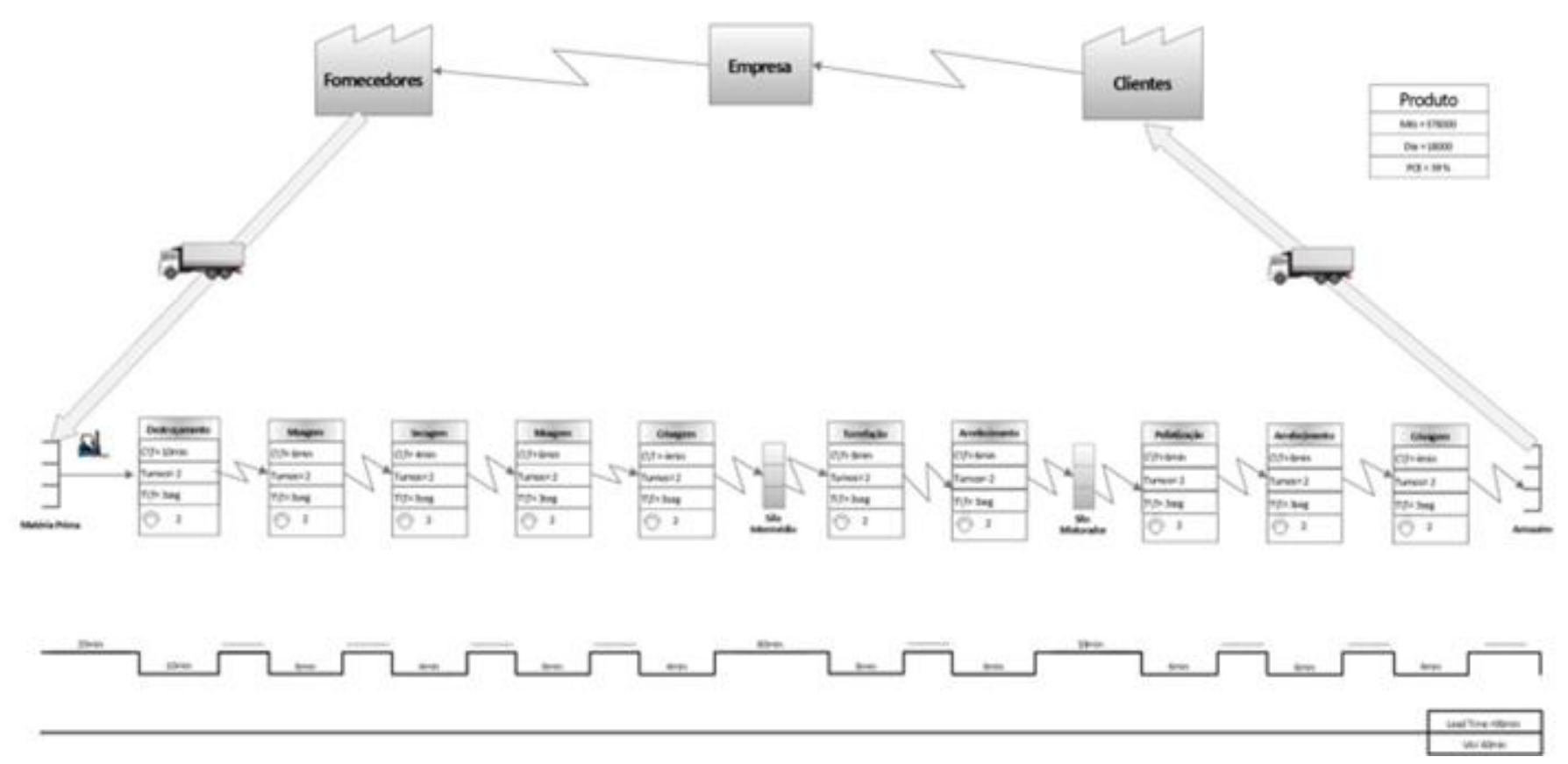

Fig. 2. VSM, improvement opportunities.

1) Shredding of the raw material. The raw material is "shredded" to the ground, having to be later used a loader, so as to collect it and place it inside the selffeeder.

2) Chip milling. The grinding consists in reducing the size and homogenizing the raw material. In the process observed, there are two mills for this purpose: one with $18 \mathrm{~mm}$ and another with $10 \mathrm{~mm}$ mesh that can be reduced.

3) Surplus of non-pelletized material. All the material that was not processed as intended is again automatically integrated into the production line immediately prior to the pelletizing process in order to be reprocessed.
After the representation of the present value stream of the production process and the analysis of the current VSM, a proposal was made for possible improvement actions to eliminate the identified wastes:

1) The proposed improvement involves putting the wrecker next to the self-feeder, which will allow the material to be placed directly into the self-feeder.

2) Chip milling. In the process observed, there are two mills for this purpose: one with aperture of $18 \mathrm{~mm}$ and another with $10 \mathrm{~mm}$, which can be reduced.

3) Surplus of non-pelletized material. All material that has not been processed as intended is re-integrated into the production line automatically.

After the representation of the present value stream of the 
production process and the analysis of the current VSM, a proposal was made for possible improvement actions to eliminate the identified wastes:

1) Change the location of the shredder by allowing the material to be placed directly into the self-feeder, facilitating and simplifying the operation, while reducing time (about 20 minutes) and resources. With this change, unnecessary use of the wheel loader is avoided, reducing the consumption of gasoil and avoiding that still residues in the ground are mixed with the material to be processed. The loader operator can perform other tasks where there is a shortage of labor.

2) Reducing the mill sieve mesh by $2 \mathrm{~mm}$ allows energy and consumable savings because the larger the particle, the harder it will be to grind, and consequently more energy and resources will be required to achieve satisfactory results.
3) The change in the compression ratio of the matrix increases the efficiency in the production of pellets, reducing the energy consumption caused by the recirculation of material.

Based on the analysis of the current VSM and in order to improve the performance of the manufacturing process, it was necessary to draw a map showing the desired situation for the value stream, responding to expected improvement expectations (Fig. 2).

\section{Future VSM Analysis}

Based on the elimination of the problems detected in the previous analysis, the future VSM was elaborated (Figure 3 ). The goal is, through a continuous flow, to produce only what is needed at the required time and eliminate all intermediate activities that do not add value to the product to the customer.

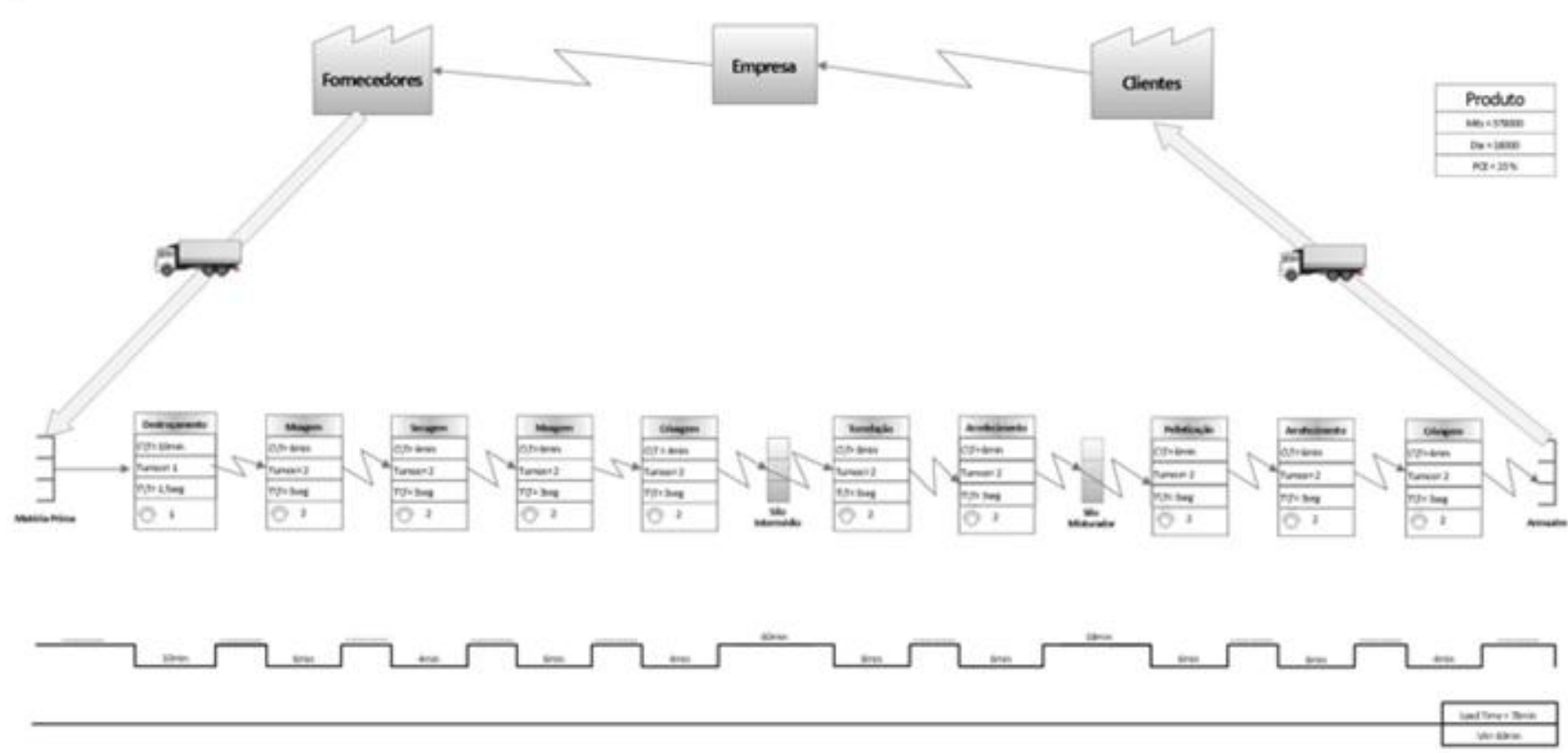

Fig. 3. VSM, future state.

After eliminating the sources of waste in the various stages of processing, and taking into account the selected metrics, the phase that presented the most significant improvements was the wrecking phase. In this step there was a decrease of time, number of operators, number of shifts and still of Tak-Time. This was due to the change in the operation of the loader, which started to collect the shredded chip directly into the self-feeder. Due to this change, the lead time decreased from 98 to 78 minutes and, consequently, the PCE increased from 39 to $23 \%$ (Equation 3) $[20]$.

$$
P C E=\frac{78-60}{78} \times 100=23 \%
$$

In addition to the design of the future VSM, it has been implemented in practice, with the integration in each process the methodologies identified as opportunities for improvement.

\section{CONCLUSIONS}

In the industry for the production of torrefied biomass pellets, it is desirable that the processes be completed efficiently and effectively. The Lean Production philosophy is a management philosophy that seeks to improve the competitiveness of organizations in order to satisfy the needs of customers, by minimizing costs, delivery times and resources (raw materials, labor, among others), The increase of the quality of the product and the involvement of all the employees of the organization, in the process of continuous improvement.

With the use of the VSM tool, it is possible to define what to do in each step of the productive process, in order to minimize resources and waste. The application of this tool aims to analyze the current state of the value chain, material flow and information and, later, to elaborate a future state with the purpose of eliminating the wastes detected in the initial analysis. 
After applying the VSM tool and eliminating the problems detected through the improvements mentioned above, there was a reduction in lead time and, consequently, in the process cycle efficiency value, since the changes effects directly influenced the reduction of time.

\section{ACKNOWLEDGMENT}

The authors are pleased to acknowledge financial support from Fundacão para a Ciência e Tecnologia and FEDER/COMPETE (grant UID/ECO/ 04007/2013).

\section{REFERENCES}

[1] N. S. Branka, Z. Cepic, and N. Dragutinovic, "Analysis of solid biomass energy potential in autonomous province of vojvodina," Renewable and Sustainable Energy Reviews, vol. 57, 2016, pp. 186191.

[2] S. Kazunobu et al., "Evaluation of biomass energy potential towards achieving sustainability in biomass energy utilization in Sabah, Malaysia," Biomass and Bioenergy, vol. 97, 2017, pp. 149-154.

[3] M. Esperanza, F. Garrido, and L. Ormaetxea, "Assessment of biomass energy potential and forest carbon stocks in biscay (Spain), " Forests, 2016.

[4] P. Dario et al., "Assessment of different feedstocks in South Tyrol (Northern Italy): Energy potential and suitability for domestic pellet boilers," Biomass and Bioenergy, vol. 90, 2016, pp. 155-162.

[5] P. Annarita and G. Lagioia, "Energy potential from residual biomass towards meeting the EU renewable energy and climate targets. The Italian case," Energy Policy, vol. 91, 2016, pp. 161-173.

[6] N. Smaragdakis, B. Z. Cepic, and N. Dragutinovic, "Analysis of solid biomass energy potential in Autonomous Province of Vojvodina." Renewable and Sustainable Energy Reviews, vol. 57, 2016, pp. 186191.

[7] P. Jostein, "Defining lean production: some conceptual and practical issues," The TQM Journal, 2009, pp. 127-142.

[8] D. H. Vries and H. M. V. D. Poll, "The influence of Lean thinking on organisational structure and behaviour in the discrete manufacturing industry," Journal of Contemporary Management, 2016, pp. 55-89.

[9] B. Stefano, R. Panizzolo, and A. M. D. Crescenzo, "Lean management and product innovation: A critical review," Understanding the Lean Enterprise, Springer International Publishing, 2016, pp. 237-260.

[10] S. Vikram, A. R. Dixit, and M. A. Qadri, "Modeling lean implementation for manufacturing sector," Journal of Modelling in Management, 2016.

[11] C. A. Habib et al., "Reduction of process lead time using lean toolvalue stream mapping (VSM)," Applied Mechanics and Materials. vol. 860, Trans Tech Publications, 2017.
[12] S. Matali et al., "Lignocellulosic biomass solid fuel properties enhancement via torrefaction," Procedia Engineering, vol. 148, 2016, pp. 671-678.

[13] Z. Y. Yi et al., "Lean-based diagnosis and improvement for offsite construction factory manufacturing facilities," in Proc. the International Symposium on Automation and Robotics in Construction, vol. 33, 2016.

[14] R. G. Bruno and M. T. Stöckli, "Going beyond triviality: The toyota production system - Lean manufacturing beyond muda and kaizen," Journal of Service Science and Management, vol. 9, no. 2, 2016.

[15] M. P. Singh, "Ramphool meena, and avinash panwar,"A Survey on the adoption of lean practices in Indian manufacturing sector," International Journal of Industrial Engineering, vol. 7, no. 2, 2016, pp. 52-62.

[16] H. A. Luís, A. J. I. D.Moraes, and A. T. Simon, "Integrating sustainability indicators and Lean Manufacturing to assess manufacturing processes: Application case studies in Brazilian industry," Journal of Cleaner Production , 2016.

[17] B. Sheila, V. A. González, and T. W. Yiu, "Clean - Lean administrative processes: a case study on sediment pollution during construction," Journal of Cleaner Production, vol. 126, 2016, pp. 134-147.

[18] G. R. J. Arturo et al., "A lean six sigma framework for the reduction of ship loading commercial time in the iron ore pelletising industry," Production Planning \& Control, 2016, pp. 1-20.

[19] G. A. J. Luis, M. O. Vento, and A. A. M. Macías, "Kaizen and Lean Manufacturing," Kaizen Planning, Implementing and Controlling, Springer International Publishing, 2017.

[20] W. Sooksiri and A. Sopadang, "Integrating sustainable development, lean, and logistics concepts into a lean sustainable logistics model," International Journal of Logistics Systems and Management, vol. 26, no. 1,2017 , pp. $85-10$

Susana G. Azevedo is an associate professor with habilitation at University of Beira Interior (Portugal). Member of the Research units: CEFAGE-UBI (Center for Advanced Studies in Management and Economics). Research interests: sustainability, supply chain management, lean, green and logistics. More than 300 scientific works published in books, chapters, articles and conference proceedings. Reviewer in many journals and also international conferences. Editor-in-Chief, associate editor and editorial board member of several international journals.

Leonel J. R. Nunes is an invited assistant professor at University of Aveiro (Portugal). Research interests: sustainability, supply chain management, lean, biomass energy and biomass conversion technologies. More than 50 scientific works published in books, chapters, articles and conference proceedings. Reviewer in many journals and also international conferences. 